ORIGINAL ARTICLE

\title{
Effect of physiotherapy attendance on outcome after anterior cruciate ligament reconstruction: a pilot study
}

\author{
J A Feller, K E Webster, N F Taylor, R Payne, T Pizzari
}

Br J Sports Med 2004;38:74-77. doi: 10.1136/bjsm.2003.005181

See end of article for authors' affiliations ......................

Correspondence to: Associate Professor Feller, La Trobe University Medical Centre, Plenty Road and Kingsbury Drive, Bundoora, Victoria 3083, Australia; jfeller@osv. com.au

Accepted 16 June 2003
Background: In many centres patients are routinely referred for physiotherapy after anterior cruciate ligament $(\mathrm{ACL})$ reconstruction. However, to date the role and amount of supervised physiotherapy required has not been clearly established.

Objective: To establish whether there was any difference in outcome between a group of patients who attended physiotherapy regularly after $\mathrm{ACL}$ reconstruction and a group who attended only infrequently. Methods: Ten patients who had attended physiotherapy infrequently (mean 1.9 visits) during the first six months after $\mathrm{ACL}$ reconstructive surgery were matched for age, sex, graft type, and activity level and occupation before injury with 10 patients who had attended physiotherapy regularly (mean 26.5 visits). Outcome was assessed at 12 months using the Cincinnati knee rating system and the IKDC form.

Results: Compared with the regular physiotherapy group, patients in the minimal physiotherapy group had fewer symptoms (mean Cincinnati symptom score 46.2 v 43.4, $p=0.045$ ). There was also a trend towards higher overall Cincinnati knee scores in the minimal physiotherapy group (mean 93.7 v87.3, $\mathrm{p}=$ $0.06)$ but no difference in IKDC ratings.

Conclusion: These preliminary results indicate that some patients who choose to attend physiotherapy on a very limited basis after $\mathrm{ACL}$ reconstruction can achieve satisfactory, if not better, outcomes than patients who attend physiotherapy regularly.
$\mathrm{P}$ hysiotherapy based rehabilitation programmes are often used after anterior cruciate ligament (ACL) reconstruction surgery. ${ }^{12}$ In general, these programmes are designed to maximise function by restoring range of motion, strength, and neuromuscular coordination. Rehabilitation programmes are often intensive in terms of the number of attendances at physiotherapy. Derscheid and Feiring ${ }^{3}$ reported an average of 39 visits to a physiotherapist over 16 weeks, and Treacy et $a l^{4}$ reported an average of 60 visits to a physiotherapist over a six month period. Such levels of attendance can represent a significant commitment on the part of the patient in terms of both time and financial cost.

Several recent papers have questioned the amount of supervised physiotherapy that is required after ACL reconstruction. Patients have been documented to achieve satisfactory outcomes with fewer physiotherapy sessions and with less physiotherapy supervision of exercise programmes. ${ }^{5-8}$ On the other hand, very infrequent physiotherapy attendance has also been associated with a poorer outcome, ${ }^{4}$ whereas more frequent attendance has been associated with a better outcome. $^{9}$

The initial intent of this study was to determine whether physiotherapy attendance per se had any influence on the outcome at 12 months after ACL reconstruction. We had planned to do this by comparing a rehabilitation programme incorporating regular physiotherapy attendance with a home based programme directed by the treating surgeon and not involving any physiotherapy attendance. Despite having ethics approval for such a design and a large potential pool of participants, it proved almost impossible to recruit patients because of a widespread belief in the patient population that physiotherapy based rehabilitation was essential to a satisfactory outcome after surgery.

In the light of the observed expectations of patients scheduled for ACL reconstruction surgery, it was felt that a pilot study was warranted. As our aim was still to determine whether a satisfactory outcome could be achieved with only minimal physiotherapy attendance after ACL reconstruction, an alternative study design was required. We therefore retrospectively identified a group of patients who had attended physiotherapy only infrequently and compared their outcome with a group who had attended physiotherapy regularly. Patients had to meet strict inclusion criteria and were matched carefully to eliminate as many confounding effects as possible.

\section{METHODS}

The study protocol was approved by the university ethics committee. To be included in the study, participants had to have had ACL reconstructive surgery between three weeks and one year after their ACL injury, no previous injury or surgery to the relevant knee, and no significant concomitant injury such as a collateral ligament injury greater than a sprain, a meniscal tear requiring repair rather than resection or no treatment, a full thickness chondral lesion, or a posterior cruciate ligament injury.

Potential participants were identified from a prospectively collated database of patients undergoing ACL reconstruction by one of two experienced knee surgeons. A total of 143 patients were identified who met the criteria for inclusion. All had surgery using either an autogenous hamstring tendon or an autogenous bone-patellar tendon-bone graft. After surgery, all patients were referred for physiotherapy at private physiotherapy clinics. The treating physiotherapists were familiar with the rehabilitation programme which emphasised early restoration of full extension and quadriceps function, and which allowed weight bearing as tolerated. Subsequent progression was essentially on an as tolerated

Abbreviations: $\mathrm{ACL}$, anterior cruciate ligament; IKDC, International Knee Documentation Committee 
basis with return to participation in some sporting activities expected from six months.

Informed consent to participate in the study was obtained from all participants.

The attendance at physiotherapy by each patient was established by a telephone interview and by examining database records of physiotherapy attendance. Patients were then classified into groups according to the number of physiotherapy attendances during the first six months after surgery: minimal physiotherapy (three or less attendances), intermediate attendance (4-11 attendances), and regular physiotherapy (12 or more attendances). It was recognised that the method of determining the number of physiotherapy attendances could be potentially inaccurate in view of its retrospective nature. However, as we were only interested in the minimal and regular groups and given the very small number of visits allowable to be included in the minimal group, we felt that the method would still yield two substantially different groups in terms of number of physiotherapy attendances. There were 10 patients in the minimal attendance group, each of whom was matched with a patient from the 69 in the regular physiotherapy group on the basis of age, sex, graft-type, occupational rating, ${ }^{10}$ and sports activity level before injury. ${ }^{11}$ These 20 patients were the final participants of the study.

Participants were assessed 12 months after the operation. The assessments were completed by one of two physiotherapists, both of whom were experienced in the examination and assessment of knees and who were blinded to the number of physiotherapy sessions each patient had attended. Patients were evaluated using the Cincinnati knee score, ${ }^{12}$ the Cincinnati occupational rating scale, ${ }^{10}$ the Cincinnati sports activity level, ${ }^{11}$ and the International Knee Documentation Committee (IKDC) form. ${ }^{13}{ }^{14}$ After the relevant questionnaires had been completed, the IKDC knee examination included goniometric measurement of active and passive flexion, and measurement of extension deficit based on the difference in heel height with the patient lying prone. ${ }^{15}$ Side to side differences in anterior knee laxity were measured with the KT-1000 arthrometer (MEDmetric Corporation, San Diego, California, USA) at $67 \mathrm{~N}$ and $134 \mathrm{~N}$.

Comparisons between the minimal physiotherapy group and the regular physiotherapy group at 12 months after surgery were made using Students $t$ test or the MannWhitney U test. In all cases the level of significance was set at $\mathrm{p}<0.05$. All comparisons were carried out using SPSS software (version 10; Chicago, Illinois, USA).

\section{RESULTS}

There were no significant differences between the minimal physiotherapy and the regular physiotherapy groups for the variables age, sex, graft type, and sports activity level and occupational rating before injury (table 1 ), indicating that the groups were well matched. Participants in the minimal physiotherapy group attended physiotherapy for a median of two visits (mean 1.9, range 0-3) in the first six months after surgery, whereas those in the regular physiotherapy group attended physiotherapy for a median of 23 visits (mean 26.5, range 15-50). None of the participants had any postoperative complications that necessitated specialised or prolonged physiotherapy. All 10 patients in the minimal physiotherapy group elected not to attend regularly of their own accord. Six did not see any need to attend physiotherapy, two attended a chiropractor, and two could not identify a reason for their choice.

Table 2 shows the Cincinnati knee scores and IKDC ratings obtained from participants at 12 months. Participants in the minimal physiotherapy group had significantly higher scores on the symptoms component of the Cincinnati scale (U(18) $=24.5, \mathrm{p}=0.045)$ and a trend towards a difference in the overall Cincinnati score $(\mathrm{p}=0.06)$. This indicated that
Table 1 Subject characteristics

\begin{tabular}{|c|c|c|}
\hline & $\begin{array}{l}\text { Minimal } \\
\text { attendance }\end{array}$ & $\begin{array}{l}\text { Regular } \\
\text { attendance }\end{array}$ \\
\hline Age (years), mean (SD) & $27.6(6.5)$ & $28.3(7.4)$ \\
\hline Male/female & 8: 2 & $8: 2$ \\
\hline Hamstring/patellar tendon graft & 4: 6 & $4: 6$ \\
\hline \multicolumn{3}{|c|}{$\begin{array}{l}\text { Time from injury to surgery } \\
\text { (weeks) }\end{array}$} \\
\hline Mean (SD) & $23.7(32)$ & $15.3(17)$ \\
\hline Median & 11.9 & 8.2 \\
\hline \multicolumn{3}{|c|}{$\begin{array}{l}\text { Preinjury sports activity level }(0- \\
100)^{*}\end{array}$} \\
\hline Mean (SD) & $86.5(6.7)$ & $87.5(10.6)$ \\
\hline Median & 85 & 85 \\
\hline \multicolumn{3}{|c|}{$\begin{array}{l}\text { Preinjury occupational rating } 10- \\
60)+\end{array}$} \\
\hline Mean (SD) & $27.0(10.4)$ & $19.2(11.3)$ \\
\hline Median & 29 & 18 \\
\hline \multicolumn{3}{|c|}{$\begin{array}{l}\text { *Higher scores on the sports activity level indicate higher function. } \\
\text { †Higher scores on the occupational rating indicate more physically } \\
\text { demanding work. }\end{array}$} \\
\hline
\end{tabular}

participants in the minimal physiotherapy group experienced fewer symptoms and a better overall outcome at 12 months than those in the regular physiotherapy group. There was no significant difference between groups for the functional component of the Cincinnati score. There were also no significant differences between groups in terms of IKDC scores.

Sports activity levels after surgery were similar for the two groups (minimal group, mean score of 79; regular group, mean score of 80), and there was also no significant difference in occupational rating after surgery (minimal

Table 2 Cincinnati knee scores and IKDC ratings 12 months after anterior cruciate ligament reconstruction

\begin{tabular}{|c|c|c|}
\hline & Minimal at & Regular attendance \\
\hline \multicolumn{3}{|c|}{ Overall Cincinnati (0-100) } \\
\hline Mean (SD) & $93.7(4.9)$ & $87.3(5.8)$ \\
\hline Median & 92 & 87 \\
\hline \multicolumn{3}{|c|}{ Cincinnati symptoms $(0-50)$} \\
\hline Mean (SD) & $46.2(2.2)$ & $43.0(3.2)^{*}$ \\
\hline Median & 46 & 44 \\
\hline \multicolumn{3}{|c|}{ Cincinnati function (0-50) } \\
\hline Mean (SD) & $47.5(4.0)$ & $44.3(3.8)$ \\
\hline Median & 46 & 45 \\
\hline \multicolumn{3}{|c|}{ Overall IKDC (no of patients) } \\
\hline A & 2 & 0 \\
\hline B & 7 & 7 \\
\hline C & 1 & 2 \\
\hline D & 0 & 1 \\
\hline \multicolumn{3}{|c|}{ IKDC 1 (subjective assessment) } \\
\hline A & 3 & 0 \\
\hline B & 7 & 10 \\
\hline C & 0 & 0 \\
\hline D & 0 & 0 \\
\hline \multicolumn{3}{|c|}{ IKDC 2 (symptoms) } \\
\hline A & 6 & 2 \\
\hline B & 3 & 5 \\
\hline C & 1 & 2 \\
\hline D & 0 & 1 \\
\hline \multicolumn{3}{|c|}{ IKDC 3 (range of motion) } \\
\hline A & 8 & 6 \\
\hline$B$ & 2 & 4 \\
\hline C & 0 & 0 \\
\hline D & 0 & 0 \\
\hline \multicolumn{3}{|c|}{ IKDC 4 (ligament examination) } \\
\hline A & 8 & 7 \\
\hline B & 2 & 3 \\
\hline C & 0 & 0 \\
\hline D & 0 & 0 \\
\hline
\end{tabular}


group, mean of 26; regular group, mean of 19). There was no significant difference between the groups for range of motion and laxity measurements (table 3 ).

\section{DISCUSSION}

Twelve months after ACL reconstruction, patients in both the minimal and regular physiotherapy groups had few symptoms and good function of the reconstructed knee, as evidenced by high Cincinnati scores and the IKDC ratings. Both groups had resumed sport at levels similar to those before their injury. The results also show that the minimal physiotherapy group achieved higher Cincinnati knee symptom scores and showed a trend towards higher overall Cincinnati knee scores.

The findings of our study were in contrast with those of Treacy et al. ${ }^{4}$ Despite finding equally good outcomes for patients who attended on a mean of both 12 and 60 occasions, the authors found that a subgroup of patients who attended physiotherapy a mean of 1.7 times fared worse in terms of Lysholm score, patient satisfaction, and return to previous activity level. They recommended a general reduction in the level of physiotherapy visits, but concluded that a certain level of supervision was still necessary. In contrast, our minimal attendance group averaged only 1.9 physiotherapy sessions but still achieved outcomes as good as, if not better than, those attending an average of 26.5 visits. In this respect our results are similar to the trial conducted by Schenck et al, ${ }^{5}$ who found no differences in functional or subjective outcomes between two groups who averaged 2.9 and 14.2 physiotherapy attendances respectively during the first six weeks after ACL reconstruction.

An important consideration in the interpretation of the results of Treacy et $a l^{4}$ was that their minimal attendance group attended public hospitals, whereas their regular physiotherapy groups attended a private clinic. They noted that most of those attending the public hospital relied on public transport and often chose not to continue with therapy when able to walk effectively. In contrast, in our study all participants received similar initial management in private hospitals and were prescribed similar care in the private physiotherapy sector.

There are a number of factors that may influence a patient's decision to attend physiotherapy. All patients in the minimal physiotherapy group in this study elected not to attend physiotherapy themselves. However, this does not necessarily imply non-adherence to a rehabilitation programme. Indeed, satisfactory progress may provide a reason

Table 3 Range of motion and anterior knee laxity data

\begin{tabular}{|c|c|c|}
\hline & Minimal aftendance & Regular attendance \\
\hline \multicolumn{3}{|c|}{ Extension deficit ${ }^{*}\left({ }^{\circ}\right)$} \\
\hline Mean (SD) & $1.0(1.7)$ & $1.8(1.9)$ \\
\hline Range & $-1.7-3.5$ & $-1.7-4.7$ \\
\hline \multicolumn{3}{|c|}{ Active flexion deficitt $\left({ }^{\circ}\right)$} \\
\hline Mean (SD) & $3.4(4.2)$ & $1.5(3.3)$ \\
\hline Range & $-2-10$ & $-5-6$ \\
\hline \multicolumn{3}{|c|}{ Passive flexion deficitt $\left({ }^{\circ}\right)$} \\
\hline Mean (SD) & $3.5(4.7)$ & $3.8(5.1)$ \\
\hline Range & $0-15$ & $0-15$ \\
\hline \multicolumn{3}{|c|}{$\mathrm{KT}-1000 \ddagger 67 \mathrm{~N}(\mathrm{~mm})$} \\
\hline Mean (SD) & $0.6(1.4)$ & $1.0(1.2)$ \\
\hline Range & $-2-3$ & $-1-3$ \\
\hline \multicolumn{3}{|c|}{ KT- $1000 \ddagger 134 \mathrm{~N}(\mathrm{~mm})$} \\
\hline Mean (SD) & $1.5(1.7)$ & $2.1(1.6)$ \\
\hline Range & $0-5$ & $0-5$ \\
\hline
\end{tabular}

*Loss of hyperextension compared with the unoperated knee. tLoss of flexion compared with the unoperated knee.

$\ddagger$ Side to side difference in anterior tibial translation.

\section{Take home message}

These preliminary results indicate that some patients who choose to attend physiotherapy on only a limited basis can achieve good outcomes 12 months after $\mathrm{ACL}$ reconstruction.

not to attend physiotherapy regularly. In other circumstances, geographic or financial constraints may restrict a patient's attendance. It should also be noted that outcome was only assessed at one point in time (12 months), and therefore the effect of physiotherapy attendance on short term goals such as the rate of progression as well as on longer term outcome remains to be investigated.

The main benefit of this study is that it has shown that certain patients may do well with minimal attendance at physiotherapy. This suggests that there may be a role for ACL rehabilitation programmes to be more individualised. There has been a tendency in ACL rehabilitation protocols for clinicians to take a recipe-type approach with time lines and even frequency to be applied to all patients. ${ }^{4{ }^{16}{ }^{17} \mathrm{~A}}$ physiotherapist could individualise the programme by working closely with patients when setting goals and by adjusting the programme to the patient's situation and progress. ${ }^{18}$ The benefits to the patient of a tailored programme could be both financial and time saving.

The main limitation of our study is of course that the patient groups were not randomised. This introduced the potential for selection bias in that patients who were having more difficulties may have attended physiotherapy more frequently than had they been progressing more smoothly. As described in the introduction, randomisation of patients had been our initial plan, but this proved to be unworkable because of patients' expectations that attendance at physiotherapy was necessary to achieve a satisfactory outcome after surgery. We therefore elected to compare patients who had attended either minimally or regularly, deliberately excluding an intermediate group of patients in an attempt to make the distinction between the two study groups more clear cut. Although we matched the two groups for age, sex, and graft type as well for sports activity level and occupational rating before injury, it is possible that there may have still been variables for which we did not match, such as motivational level and rate of progress.

Despite the potential shortcomings in terms of design, the findings of this study do nonetheless show that some patients who choose to attend physiotherapy on a limited basis can achieve good outcomes at 12 months after ACL reconstruction. This finding emphasises that there is still a need for a randomised controlled trial to evaluate the role of physiotherapy after ACL reconstruction. The results from this study may help patients to consider taking part in such a study in the future.

\section{Authors' affiliations}

J A Feller, K E Webster, N F Taylor, R Payne, T Pizzari, Musculoskeletal Research Centre, La Trobe University, Melbourne, Victoria, Australia

\section{REFERENCES}

1 Delay BS, Smolinski RJ, Wind WM, et al. Current practices and opinions in $\mathrm{ACL}$ reconstruction and rehabilitation: results of a survey of the American Orthopaedic Society for Sports Medicine. Am J Knee Surg $2001 ; 14: 85-91$.

2 Feller J, Cooper R, Webster K. Current Australian trends in rehabilitation following anterior cruciate ligament reconstruction. The Knee 2002;9:121-6.

3 Derscheid G, Feiring D. A statistical analysis to characterize treatment adherence of the 18 most common diagnoses at a sports medicine clinic. J Orthop Sports Phys Ther 1987;9:40-6. 
4 Treacy SH, Barron OA, Brunet ME, et al. Assessing the need for extensive supervised rehabilitation following arthroscopic $\mathrm{ACL}$ reconstruction. Am J Orthop 1997;26:25-9.

5 Schenck RC Jr, Blaschak MJ, Lance ED, et al. A prospective outcome study of rehabilitation programs and anterior cruciate ligament reconstruction. Arthroscopy 1997;13:285-90.

6 Fischer DA, Tewes DP, Boyd JL, et al. Home based rehabilitation for anterior cruciate ligament reconstruction. Clin Orthop 1998;347:194-9.

7 Beard DJ, Dodd CA. Home or supervised rehabilitation following anterior cruciate ligament reconstruction: a randomized controlled trial. J Orthop Sports Phys Ther 1998;27:134-43.

8 DeCarlo M, Sell K. The effects of the number and frequency of physical therapy treatments on selected outcomes of patients with anterior cruciate ligament reconstruction. J Orthop Sports Phys Ther 1997;26:332-9.

9 Frosch $\mathrm{KH}$, Habermann F, Fuchs $M$, et al. Is prolonged ambulatory physical therapy after anterior cruciate ligament-plasty indicated? Comparison of costs and benefits. Unfallchirurg 2001;104:513-18.

10 Noyes FR, Mooar LA, Barber SD. The assessment of work-related activities and limitations in knee disorders. Am J Sports Med $1991 ; 19: 178-88$.
11 Noyes FR, Barber SD, Mooar LA. A rationale for assessing sports activity levels and limitations in knee disorders. Clin Orthop 1989;246:238-49.

12 Noyes FR, Mooar PA, Matthews DS, et al. The symptomatic anterior cruciatedeficient knee. Part I: the long-term functional disability in athletically active individuals. J Bone Joint Surg [Am] 1983;65:154-62.

13 Hefti F, Muller W, Jakob RP, et al. Evaluation of knee ligament injuries with the IKDC form. Knee Surg Sports Traumatol Arthrosc 1993;1:226-34.

14 Irrgang JJ, $\mathrm{Ho} \mathrm{H}$, Harner CD, et al. Use of the International Knee Documentation Committee guidelines to assess outcome following anterior cruciate ligament reconstruction. Knee Surg Sports Traumatol Arthrosc 1998;6:107-14.

15 Sachs RA, Daniel DM, Stone ML, et al. Patellofemoral problems after anterior cruciate ligament reconstruction. Am J Sports Med 1989; 17:760-5.

16 Lai E, Ng G. A survey on the rehabilitative management of anterior cruciate ligament injuries in Hong Kong. Hong Kong Physiotherapy Journal 1997; 15:15-21.

17 Brukner P, Khan K. Clinical sports medicine, 2nd ed. Sydney: McGraw-Hill, 2001.

18 Pizzari T, McBurney $\mathrm{H}$, Taylor $\mathrm{N}$, et al. Adherence to anterior cruciate ligament rehabilitation: a qualitative analysis. Journal of Sport Rehabilitation 2002;11:89-101.
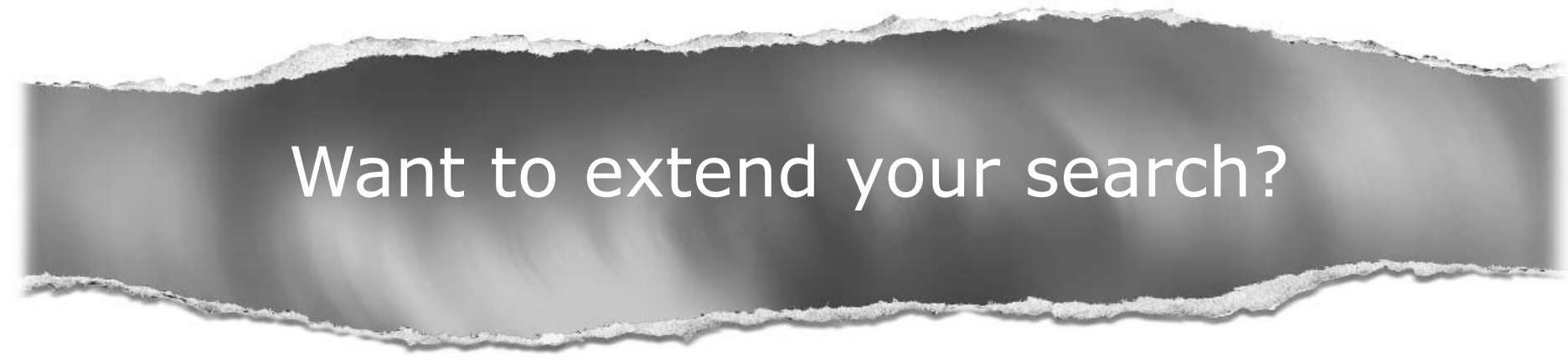

Cross journal searching

Can't find what you're looking for in British Journal of Sports Medicine? Extend your search across 340+ journals. Search restriction options include specific subject areas (eg. clinical medicine, basic research),

select specific journals or search all available titles.

\section{www.bjsportmed.com}

